Article

\title{
Phenolic Compounds Characterization and Biological Activities of Citrus aurantium Bloom
}

\author{
Ehsan Karimi ${ }^{1}$, Ehsan Oskoueian ${ }^{1}$, Rudi Hendra ${ }^{2}$, Armin Oskoueian ${ }^{3}$ and Hawa Z. E. Jaafar ${ }^{4, *}$ \\ 1 Department of Science, Science and Research Branch, Islamic Azad University, Tehran 14515, Iran \\ 2 Department of Chemistry, Faculty of Mathematic and Natural Sciences, University of Riau, \\ Pekanbaru, Riau 28143, Indonesia \\ 3 Department of Agronomy, Faculty of Agriculture, Islamic Azad University, Mashhad Branch, \\ Mashhad 91735-413, Iran \\ 4 Department of Crop Science, Faculty of Agriculture, University Putra Malaysia, Serdang, \\ Selangor 43400, Malaysia \\ * Author to whom correspondence should be addressed; E-Mails: hawazej@gmail.com; \\ hawazej@agri.upm.edu; Tel.: +6-03-8946-6922/6-012-372-3585; Fax: +6-03-8943-5973.
}

Received: 14 November 2011; in revised form: 22 December 2011 / Accepted: 23 December 2011 / Published: 30 January 2012

\begin{abstract}
Citrus plants are known to possess beneficial biological activities for human health. In addition, ethnopharmacological application of plants is a good tool to explore their bioactivities and active compounds. This research was carried out to evaluate the phenolic and flavonoid analysis, antioxidant properties, anti inflammatory and anti cancer activity of Citrus aurantium bloom. The total phenolics and flavonoids results revealed that methanolic extract contained high total phenolics and flavonoids compared to ethanolic and boiling water extracts. The obtained total phenolics value for methanolic Citrus aurantium bloom extract was $4.55 \pm 0.05 \mathrm{mg}$ gallic acid equivalent (GAE)/g dry weight (DW), and for total flavonoids it was $3.83 \pm 0.05 \mathrm{mg}$ rutin equivalent/g DW. In addition, the RP-HPLC analyses of phenolics and flavonoids indicated the presence of gallic acid, pyrogallol, syringic acid, caffeic acid, rutin, quercetin and naringin as bioactive compounds. The antioxidant activity of Citrus aurantium bloom were examined by the 1,1-diphenyl-2-picryl-hydrazyl (DPPH) assay and the ferric reducing/antioxidant potential (FRAP). The free radical scavenging and ferric reducing power activities were higher for the methanolic extract of Citrus aurantium bloom at a concentration of $300 \mu \mathrm{g} / \mathrm{mL}$, with values of $55.3 \%$ and $51.7 \%$, respectively, as compared to the corresponding boiling water and ethanolic extracts, but the activities were lower than those of antioxidant standards
\end{abstract}


such as BHT and $\alpha$-tocopherol. Furthermore, the anti-inflammatory result of methanolic extract showed appreciable reduction in nitric oxide production of stimulated RAW 264.7 cells at the presence of plant extract. Apart from that, the anticancer activity of the methanolic extract was investigated in vitro against human cancer cell lines (MCF-7; MDA-MB-231), human colon adenocarcinoma (HT-29) and Chang cell as a normal human hepatocyte. The obtained result demonstrated the moderate to appreciable activities against all cell line tested and the compounds present in the extracts are non-toxic which make them suitable as potential therapeutics.

Keywords: Citrus aurantium bloom; HPLC; antioxidant properties; anti-inflammatory and anticancer activity

\section{Introduction}

Nowadays, the study of oxygen-containing free radicals in humans and their roles has been a growing interest among scientists. The conclusion has been that these radicals may contribute as factors in decreasing the immune system function [1]. Synthetic antioxidants such as butylated hydroxytoluene (BHT) and butylated hydroxyanisole (BHA) are known to posses free radical inhibition properties in the human body, but these compounds can also be toxic and present hazards to the human body as well [2]. Fruits and vegetables are rich of secondary metabolites such as phenolics which are now identified as natural antioxidant agents. Phenolic compounds have been shown to possess an antioxidant activity based on their (hydroxyl group) donation to free radicals. Moreover, phenolic compounds also possess a wide spectrum of biological activities such as antimutagenic, anticarcinogenic, anti-inflammation, antiallergic, as well as the ability to modify gene expression [3-10].

Citrus is one of larges species among plant; it consists of 40 species which are distributed in all continents [11]. Citrus is one of the most important fruits, which is consumed mostly fresh and has been used as a herbal medicine or additive or food supplement. Citrus is believed to possess bioactivities such as antioxidant, anti-inflammatory, antimicrobial, and is suggested to be responsible for the prevention of cancer and degenerative diseases [12]. Those bioactivities of citrus are due to the present of bioactive compound such as phenolics, flavonoids, essential oil, and vitamins [13]. Bloom of Citrus aurantium has long history of usage and is believed to alleviate the heart diseases, anti-depressant and tonic among people living in the north of Iran. Information about possible bioactivities of this part of the plant is rather limited, therefore an experiment was conducted to determine phytochemical analysis including phenolic and flavonoid compounds and their biological activities such as antioxidant properties, anti inflammatory and anticancer activities.

\section{Results and Discussion}

\subsection{Total Phenolic and Flavonoid Contents}

The results of total phenolic and flavonoid contents are shown in Table 1. The results obtained showed that methanolic extract of citrus bloom contains high total phenolic and flavonoid contents 
compared to the ethanolic and hot water extract, with a value of $4.8 \pm 0.05 \mathrm{mg}$ gallic acid equivalent/g DW and $4.1 \pm 0.05 \mathrm{mg}$ rutin equivalent/g DW. The total phenolic contents obtained was found to be lower compared to total phenolic content from C. aurantium peel, with a value of $223.2 \mathrm{mg}$ gallic acid equivalent/g while the total flavonoid contents were found to be lower, with a value of $7.7 \mathrm{mg}$ quercetin equivalent/g [14]. Previous studies have reported that solvents such as methanol, ethanol, acetone, ethyl acetate in combination of water have usually been used for the extraction of phenolic and flavonoid contents from plants [15]. Furthermore, the polarity of solvent are also one of interest in the processing of phenolics and flavonoid extraction [16]. Due to the mentioned reasons, it is difficult to choose a standard extraction method suitable for the extraction of phenolic and flavonoids from plants. Usually, the least polar solvents are considered to be suitable for the extraction of phenolic and flavonoid contents. The results in Table 1 indicated that methanol was a highly efficient solvent to extract phenolic and flavonoid contents among the solvents used in this study. The findings were in agreement with Perez et al. [17] who found that ethanol and water were less efficient solvents for extracting phenolic compounds compared to methanol. Moreover, Karimi et al. [18] and Oskoueian et al. [19] also observed the highest phenolic, flavonoid and antioxidant activity in the crude methanolic extract of saffron stigma and Jatropha curcas leaf, root and stem bark as compared to ethanol and water. Therefore, this research shows that different extracting solvents influenced different levels of total phenolic and flavonoid compound in present study.

Table 1. Total phenolic and flavonoids content of Citrus aurantium bloom.

\begin{tabular}{ccc}
\hline Solvent & Phenolic Content ${ }^{1}$ & Flavonoid Content $^{2}$ \\
\hline Ethanol & $4.55 \pm 0.005^{\mathrm{b}}$ & $3.83 \pm 0.05^{\mathrm{b}}$ \\
Water & $3.93 \pm 0.58^{\mathrm{c}}$ & $1.88 \pm 0.01^{\mathrm{c}}$ \\
Methanol & $4.83 \pm 0.05^{\mathrm{a}}$ & $4.11 \pm 0.05^{\mathrm{a}}$ \\
\hline mg gallic acid equivalent/g DW; ${ }^{2}$ mg rutin equivalent/g DW; $\mathrm{n}=3$. Means within the same \\
clumn with different letters are significantly different $(p<0.05)$.
\end{tabular}

\subsection{Determination of Phenolic and Flavonoid Compounds by HPLC}

Reversed-phase (RP) chromatography was used to determine of phenolic and flavonoid compounds presented in citrus extract. The phenolic and flavonoid compounds were identified based on their retention times and quantified according to respective standard calibration curves (Figures 1 and 2). The HPLC chromatogram revealed that gallic acid, pyrogallol, syringic acid and caffeic acid were the major phenolic compounds present in $C$. aurantium bloom with values of $212.4 \pm 0.02 \mu \mathrm{g} / \mathrm{g} \mathrm{DW}$, $541.27 \pm 0.03 \mu \mathrm{g} / \mathrm{g}$ DW, $269.04 \pm 0.05 \mu \mathrm{g} / \mathrm{g}$ DW, and $249.9 \pm 0.05 \mu \mathrm{g} / \mathrm{g} \mathrm{DW}$, respectively, while rutin, quercetin and naringin were detected as the major flavonoid compounds, with values of $362.8 \pm 0.02$, $185.37 \pm 0.11$ and $688.1 \pm 0.05 \mu \mathrm{g} / \mathrm{g}$ DW (Tables 2 and 3). Figure 3 shows a chromatogram of a mixture of standards. These findings are supported by Peleg et al. [20] who reported the presence of gallic acid, caffeic acid in several species of citrus. This result revealed that gallic acid, and other phenolic and flavonoid compounds may be responsible for the antioxidant activity in this plant and suggested that there seemed to be a good correlation among these compounds and antioxidant activity and other biological activity in this plant. 
Figure 1. The RP-HPLC chromatogram of flavonoid compounds in methanolic extract of Citrus aurantium bloom. Identified compounds: Rutin, naringin and quercetin.

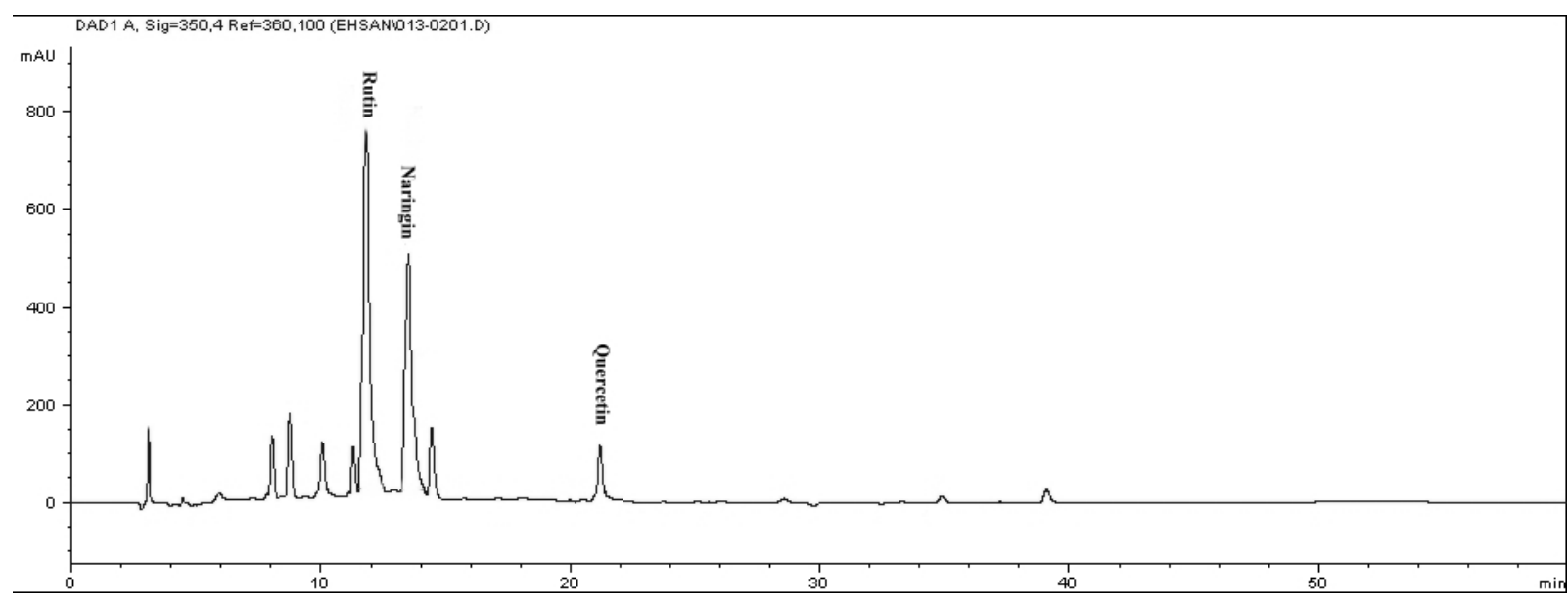

Figure 2. The RP-HPLC chromatogram of phenolic compounds in methanolic extract of Citrus aurantium bloom. Identified compounds: Gallic acid, pyrogallol, syringic acid and caffeic acid.

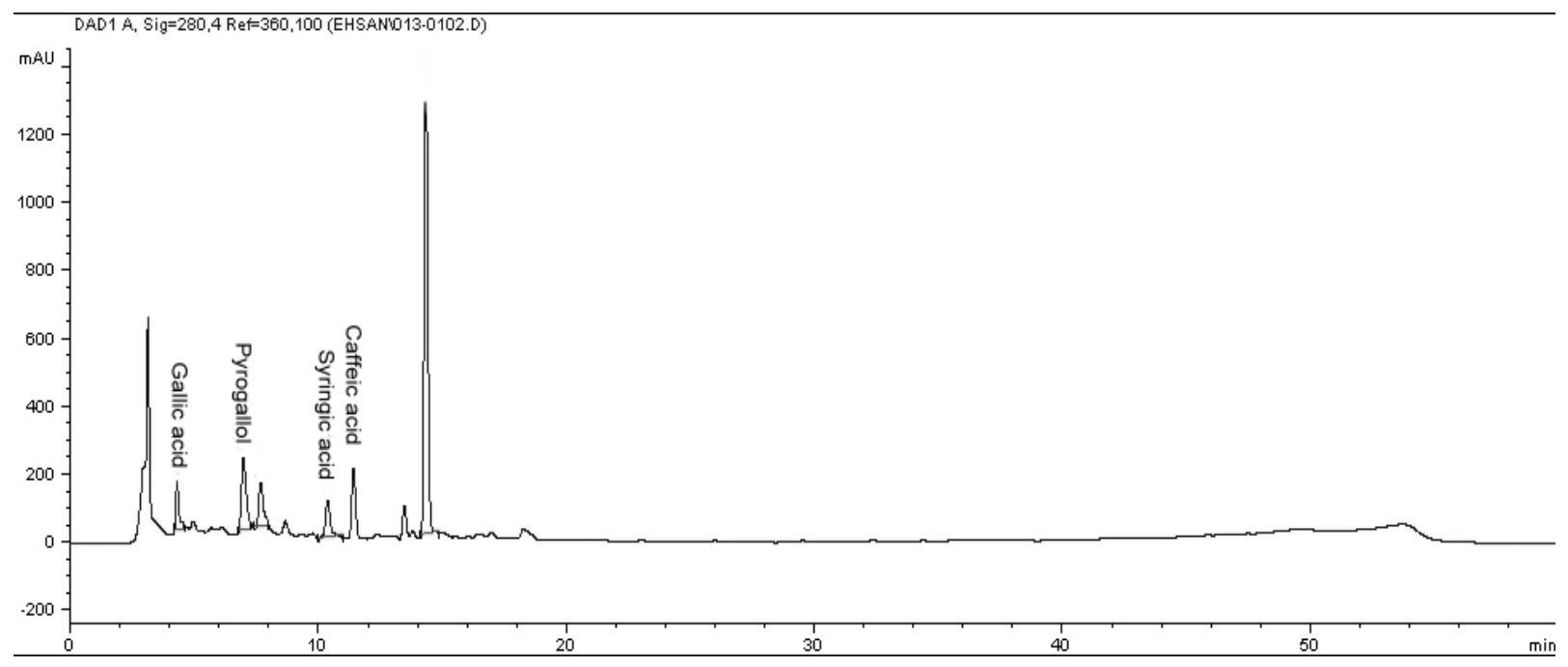

Table 2. Phenolic compounds of methanolic extract of Citrus aurantium bloom.

\begin{tabular}{ccccccc}
\hline \multirow{2}{*}{ Sample } & \multicolumn{5}{c}{ Phenolic contents ( $\boldsymbol{\mu g} / \mathbf{g}$ dry sample) } \\
\cline { 2 - 6 } & Gallic acid & Pyrogallol & Salicylic acid & Caffeic acid & Vanillic acid & Syringic acid \\
\hline C. Aurantium bloom & $212.42 \pm 0.02$ & $541.27 \pm 0.03$ & ND & $249.95 \pm 0.05$ & ND & $269.04 \pm 0.05$ \\
\hline
\end{tabular}

ND: not detected.

Table 3. Flavonoid compounds of methanolic extract of Citrus aurantium bloom.

\begin{tabular}{ccccccc}
\hline \multirow{2}{*}{ Sample } & \multicolumn{5}{c}{ Flavonoid contents ( $\boldsymbol{\mu g} / \mathbf{g}$ dry sample) } \\
\cline { 2 - 7 } & Apigenin & Kaempferol & Myricetin & Naringin & Quercetin & Rutin \\
\hline C. Aurantium bloom & ND & ND & ND & $688.11 \pm 0.05$ & $185.37 \pm 0.11$ & $362.85 \pm 0.01$ \\
\hline
\end{tabular}

ND: not detected. 
Figure 3. Chromatogram of flavonoids mixture of the standards detected at $350 \mathrm{~nm}$ by RP-HPLC: 11.76-rutin, 14.12-naringin, 17.67-myricetin, 21.854-quercetin, 24.85-apigenin and 25.909-kaempferol.

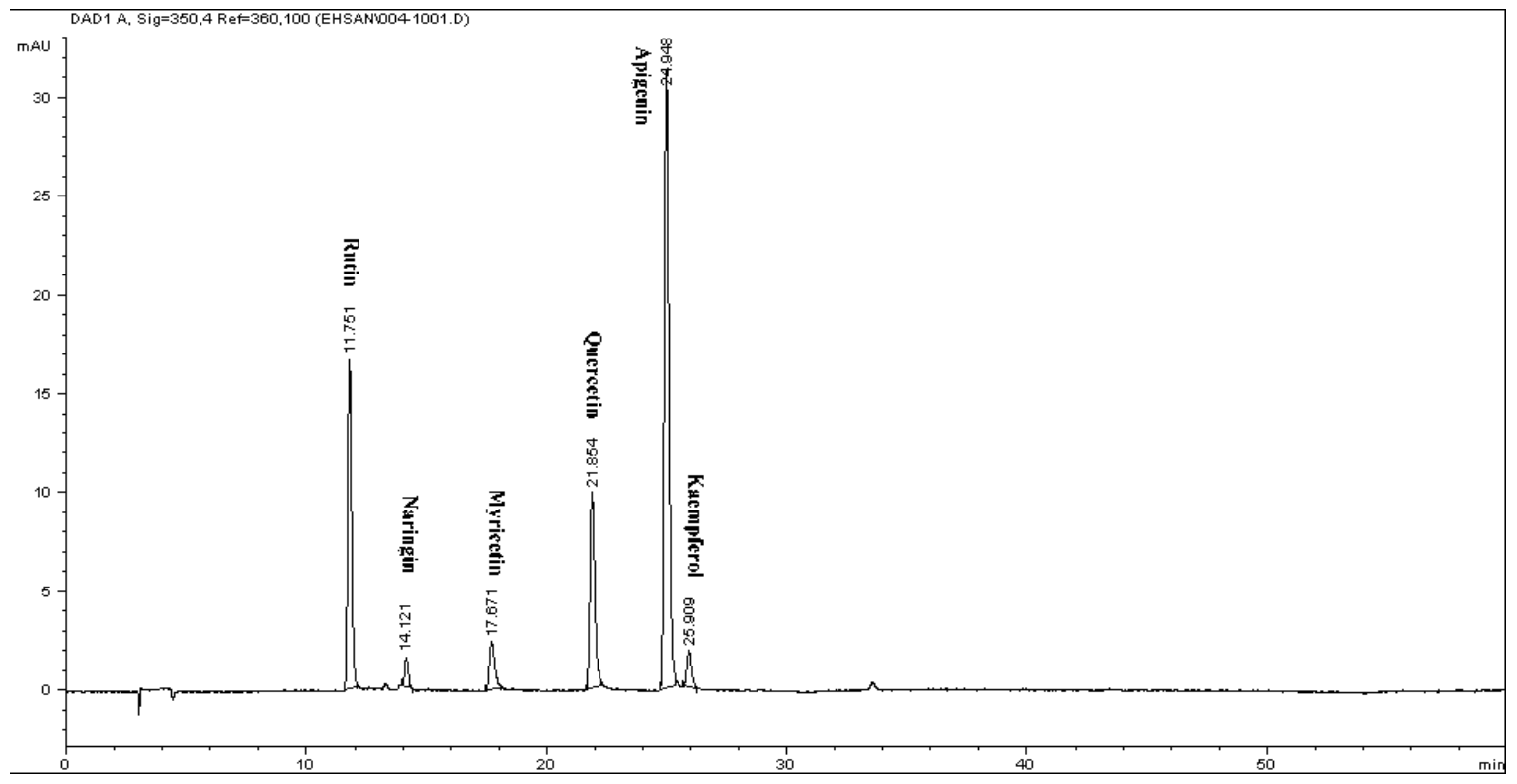

\subsection{Antioxidant Activity Determination}

Antioxidant research is a key topic in both the medical and food industry today. Antioxidants protect the body from reactive species. Previous researches have indicated the linear positive correlation between bioactive compounds of plant materials with their antioxidant capacities [21]. The antioxidant activities of Citrus aurantium Bloom determined by free radical scavenging activity (DPPH) and FRAP assay methods using different solvent polarity. The reduction of DPPH radical was followed by monitoring the decrease of absorption of sample extracts at $517 \mathrm{~nm}$. The results obtained (Figures 4 and 5) from DPPH radical-scavenging activity of $C$. aurantium bloom showed that all extracts exhibited DPPH radical inhibition activity at different concentrations. It was observed that methanolic extract show higher DPPH free radical scavenging activity compared to ethanol and hot water, with values of $55.32 \%, 52.41 \%$, and $50.46 \%$, respectively, but less than those of BHT and $\alpha$-tocopherol at $300 \mu \mathrm{g} / \mathrm{mL}$. Like the DPPH results, C. aurantium appeared to be active in the reduction of $\mathrm{Fe}^{3+}$. The ferric reducing power activity of $C$. aurantium bloom varied among the extracts, but the values were all lower than those of the standards. Methanolic extract showed a higher reductive potential than the boiling water and ethanolic extracts. The reductive potential of Citrus aurantium bloom extracts and standards at a concentration of $300 \mu \mathrm{g} / \mathrm{mL}$ (Table 4) were found to be in the ascending order: Vitamin $\mathrm{C}>\alpha$-tocopherol $>$ BHT $>$ methanol $>$ ethanol $>$ boiling water, with respective values of $96.1 \%, 92.9 \%, 89.5 \%, 51.7 \%, 47.6 \%$ and $43.5 \%$. 
Figure 4. Free radical scavenging activity of Citrus aurantium extracts using different solvents by 1,1-diphenyl-2-picrylhydrazyl radicals. $\mathrm{n}=3$.

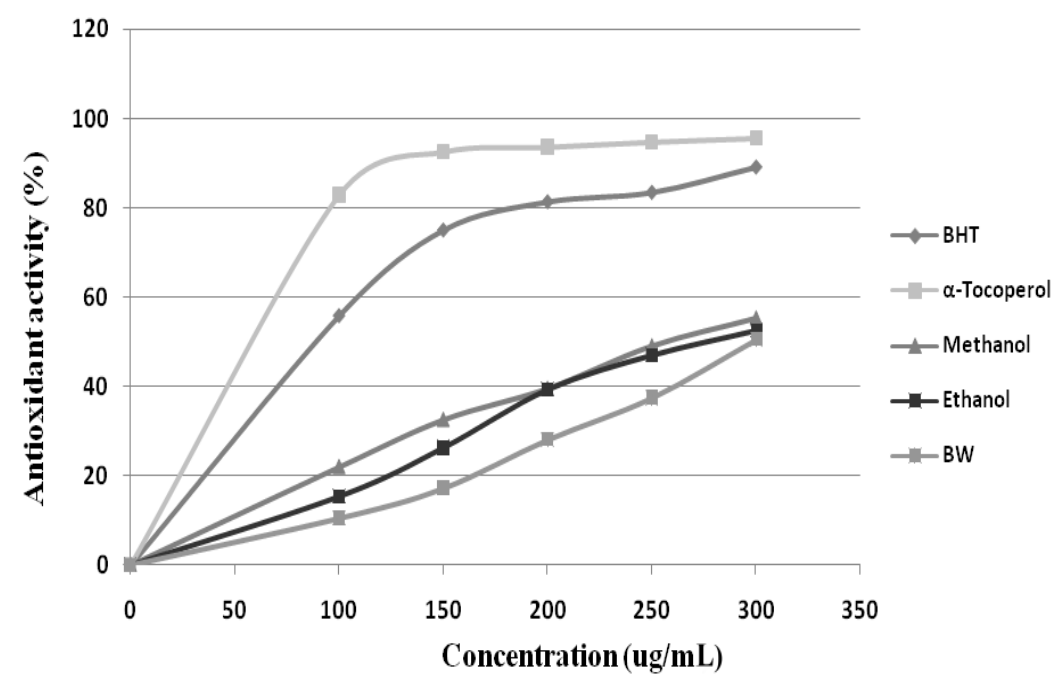

Figure 5. The free radical scavenging of Citrus aurantium bloom extracts using different solvents and reference antioxidants at $300 \mu \mathrm{g} / \mathrm{mL}$.

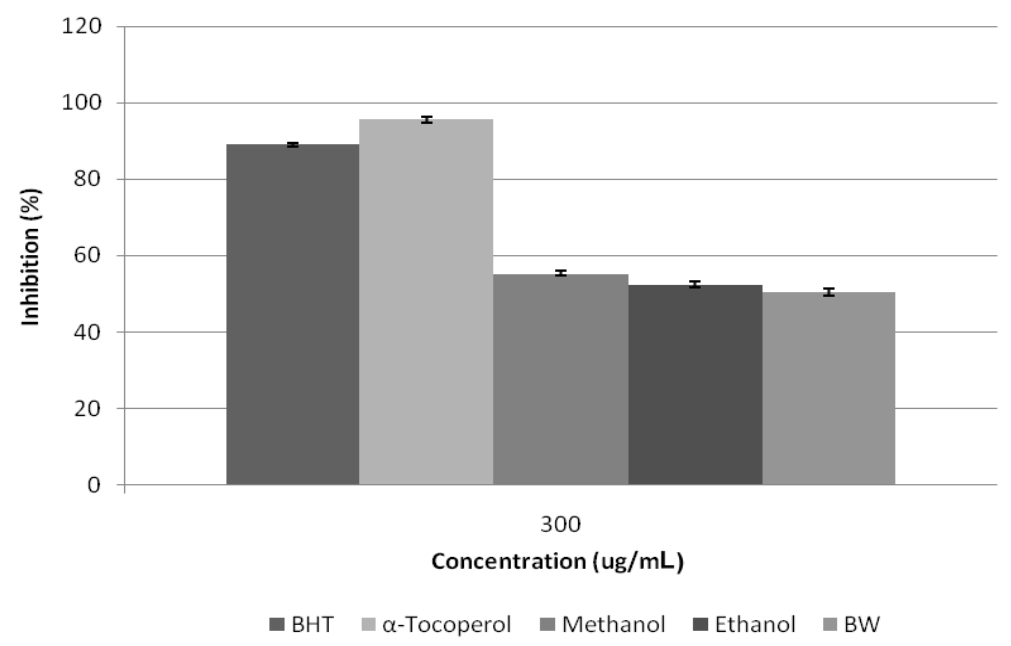

Table 4. FRAP activity of Citrus aurantium extracts using different solvents (methanol, boiling waterand ethanol). BHT, $\alpha$-tocopherol and vitamin $\mathrm{C}$ were used as positive controls.

\begin{tabular}{ccc}
\hline & Solvent used for Extraction & FRAP $(\mathbf{3 0 0} \boldsymbol{\mu g} / \mathbf{m L})$ \\
\hline \multirow{3}{*}{ Citrus aurantium Bloom } & Methanol & $51.7 \pm 37.3^{\mathrm{d}}$ \\
& Water & $43.5 \pm 23.4^{\mathrm{f}}$ \\
& Ethanol & $47.6 \pm 18.7^{\mathrm{e}}$ \\
\hline \multirow{2}{*}{ Control } & BHT & $89.5 \pm 11.2^{\mathrm{c}}$ \\
& a-tocopherol & $92.9 \pm 25.4^{\mathrm{b}}$ \\
& Vitamin C & $96.1 \pm 41.2^{\mathrm{a}}$ \\
\hline
\end{tabular}

All analyses were the mean of triplicate measurements \pm standard deviation. Results expressed in percent of antioxidant power at $300 \mu \mathrm{g} / \mathrm{mL}$. Means not sharing a common letter within a column were significantly different at $p \leq 0.05$. 
Phytochemicals are chemicals derived from plant sources. Plants contain hundreds of phytochemicals such as flavonoids and phenolic acids. Research indicates phytochemicals such as polyphenols have high antioxidant activity [22]. Free radicals are highly reactive and are generated in the body through normal cellular function and are believed to cause lipid oxidation leading to cellular membrane damage [23]. The antioxidant activity of $C$. aurantium bloom extract might be due to the present phenolic and flavonoid which have been explained above. Wang et al. [24] mentioned that phenolic such as phenolic acid and flavonoid have important role due to the ability to scavenge free radical.

Flavonoids act as "radical-scavengers" so they categorized in powerful antioxidants groups against free radicals. This activity is attributed to their hydrogen-donating ability. Indeed, the phenolic groups of flavonoids serve as a source of a readily available "H" atoms such that the subsequent radicals produced can be delocalized over the flavonoid structure [25,26]. Rapisarda et al. [27] reported the antioxidant capacity of some varieties of pigmented oranges, including Moro, Sanguinella, Tarocco and Washington. All examined orange juices show an antioxidant capacity, due to total phenol amounts and to their ability to interact with the biomembrane; their antioxidant capacity seems to be widely influenced by the anthocyanin concentrations in the pigmented oranges juices. This study shows that the daily phenol intake, as orange juice, may represent an additional protection in vivo against cellular biomolecule oxidation.

\subsection{Anti Inflammatory Activity}

The crude methanolic extracts of $C$. aurantium blooms were analyzed for their inhibitory effects on NO production from macrophages RAW 264.7 cells, induced by LPS and IFN- $\gamma$. Anti inflammatory results indicated that the production of nitric oxide was significantly inhibited by methanolic extract of C. aurantium of different concentrations (Figure 6). In the highest concentration $(100 \mu \mathrm{g} / \mathrm{mL})$, the value of nitric oxide production was $14.40 \mu \mathrm{M}$ while this value was still higher comparing to positive control (L-NAME). Even though the nitric oxide inhibitory activity of the sample was lower than the positive control the inhibition value was but still an appreciable amount. Uninduced RAW 264.7 cells showed the lowest nitric oxide production, even though the cells had not been stimulated by LPS and IFN- $\gamma$ low production of nitric oxide in normal condition. NO produced by constitutive NOS is vital for other physiological function such as neurotransmitter, blood flow, and synaptic plasticity. Furthermore, the cells without inhibitor showed the highest production of nitric oxide, this is due to the presence of inducible nitric oxide synthase (iNOS) inducers, which are LPS and IFN- $\gamma$ in the absence of any iNOS inhibitor such as L-NAME or plant extract. The MTT assay was done accordingly to test the cell viability of RAW 264.7 cells while the nitric oxide production inhibited at different concentration by plant extract. As shown in Figure 7 the cell viability was not affected while different concentrations of plant extract were applied. At the highest concentration used $(100 \mu \mathrm{g} / \mathrm{mL})$ percentage of cell viability for the extracts was still more than $90 \%$ indicating the safety of respective plant extract. C. aurantium blooms contained the highest amount of flavonoid and appreciable level of phenolics (Table 1). Sumanont et al. [28] demonstrated that the mechanism of phenolic compounds in antioxidant activity and their ability to act as free radical scavengers resulting in to formation of phenoxyl radicals. Kazlowska et al. [29] and Oskoueian et al. [19] suggested that the inhibition of iNOS in the RAW 264.7 cell, is due to the suppressing action of flavonoids. Methanolic extract of 
Parinari polyandra (main compounds were flavonoids and tannins) and Alchornea cordifolia (main compounds were flavonoids and phenolics) revealed anti-inflammatory effects at concentration of 200 and $100 \mathrm{mg} / \mathrm{kg}$ paw oedema mice respectively [30,31]. Quercetin, hesperitin and morin at each concentration of $75 \mathrm{mg} / \mathrm{kg}$ exhibited anti-inflammatory effect in carrageenan-induced paw oedema mice [32].

Figure 6. Effect of $C$. aurantium extracts at various concentration on the production of NO by LPS/IFN- $\gamma$ stimulated RAW 264.7 cells. Each bar represents the mean \pm standard error of mean from three independent experiments. $* * * p<0.0001$ indicates a significant difference from the LPS/IFN- $\gamma$ stimulated cells analyzed by using the Dunnett's Comparison Test.

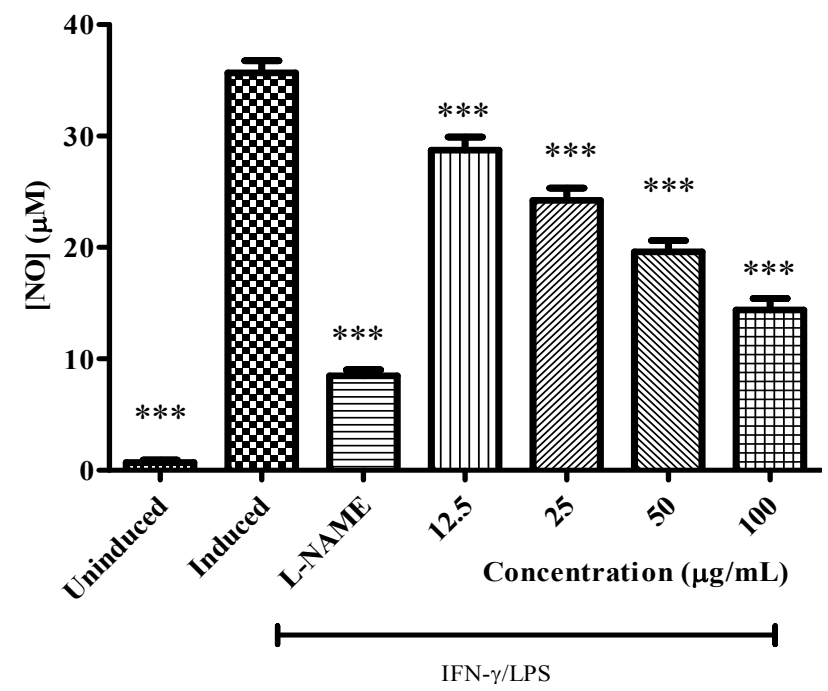

Figure 7. Effect of the C. aurantium extracts on cell viability of RAW 264.7 cells. Each bar represents the mean \pm standard error of mean from three independent experiments.

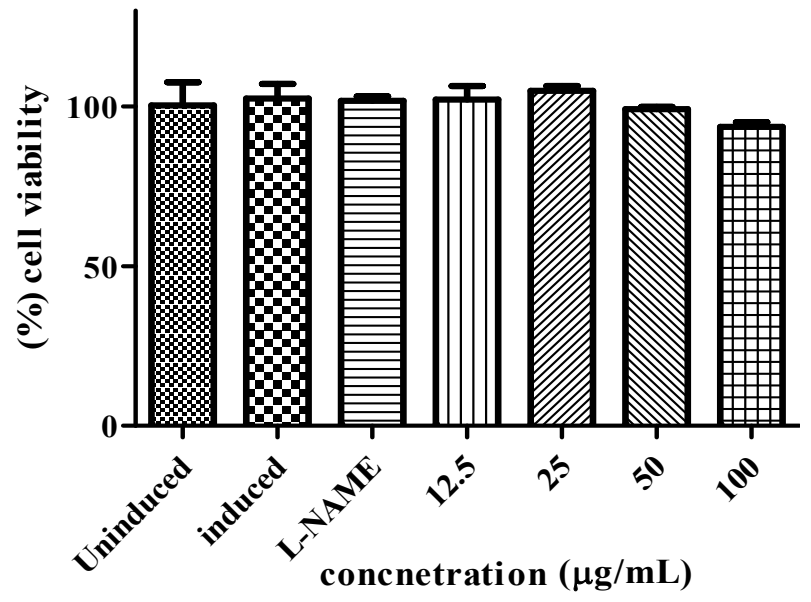

\subsection{Anti Cancer Activity}

Cancer is a group of diseases characterized by cells that grow out of control; in many cases, they form masses of cells, or tumors, that infiltrate, crowd out, and destroy normal tissue. Consumption of antioxidant rich fruits and vegetables in our daily diets significantly reduces the risk of many cancer diseases, suggesting that confident antioxidants could be effective agents for the inhibition of cancer 
spread [33]. The obtained results of anti cancer activity of $C$. aurantium extracts are shown in Figure 8. Increase in extracts concentration of up to $200 \mu \mathrm{g} / \mathrm{mL}$, could reduce the cell viabilities significantly $(p<0.001)$ in a dose-dependent manner in all four cell lines tested. The $\mathrm{IC}_{50}$ values of extracts used in this study are presented in Table 5. According to the US NCI plant screening program, a crude extract is generally considered to have in vitro cytotoxic activity if the IC50 value (concentration that causes reduction in cell viability to $50 \%$ ) is less than $30 \mu \mathrm{g} / \mathrm{mL}$ [34].

Figure 8. Effect of crude methanolic extract of Citrus blooms on Chang liver, MCF-7, MDA-MB 231 and HT-29 cells survival. All values represent the mean \pm S.E.M from three independent experiments. ${ }^{* * *} p<0.001,{ }^{* *} p<0.01$ and $* p<0.1$ indicate significant difference compared to the untreated control group.

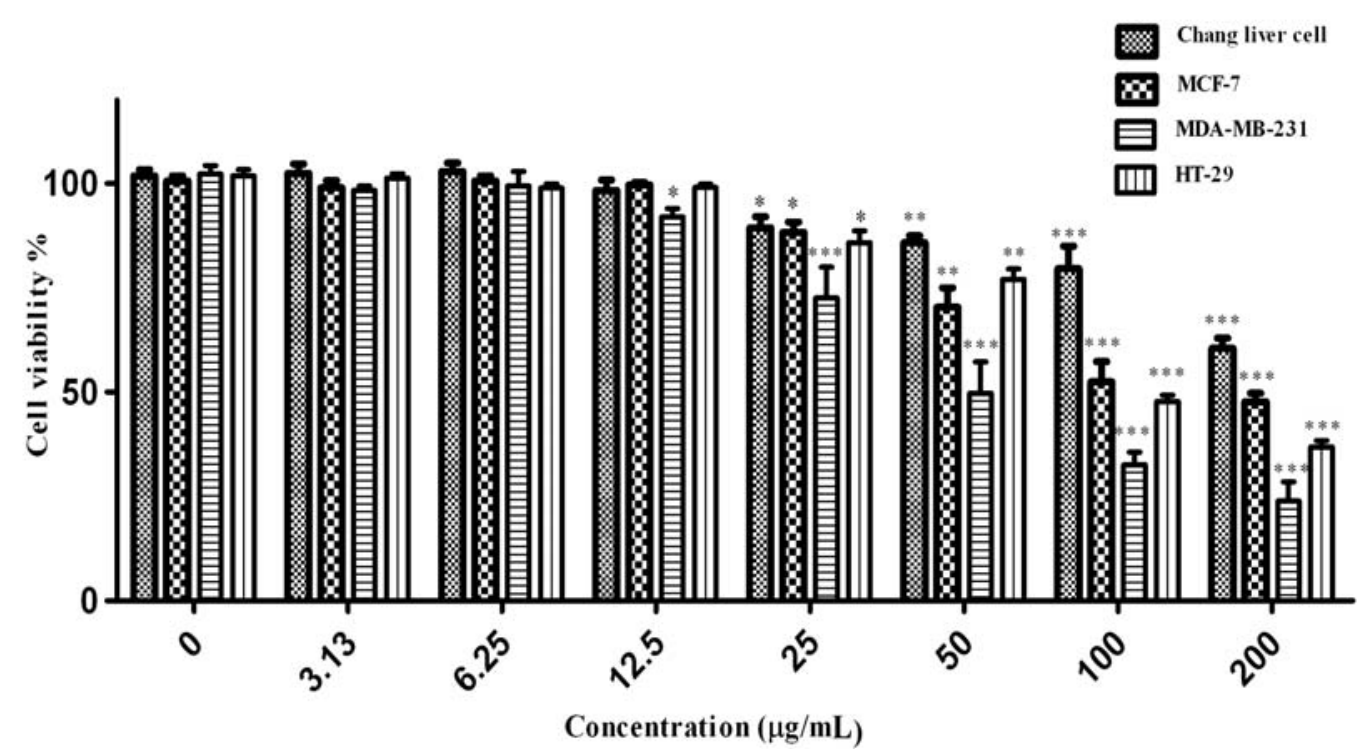

Table 5. The IC50 values of extracts and positive control on Chang liver, MCF-7, MDA-MB 231 and HT-29 cell lines.

\begin{tabular}{ccccc}
\hline \multirow{2}{*}{ Sample } & \multicolumn{4}{c}{ IC50 value $(\boldsymbol{\mu g} / \mathbf{m L})$} \\
\cline { 2 - 5 } & Chang liver & MCF-7 & MDA-MB 231 & HT-29 \\
\hline Citrus aurantium Blooms & $>200$ & $152.34 \pm 0.75$ & $49.74 \pm 0.75$ & $96.23 \pm 0.75$ \\
Tamoxifen & $45.07 \pm 2.59$ & $17.31 \pm 0.93$ & $17.51 \pm 0.25$ & $18.11 \pm 0.89$ \\
\hline
\end{tabular}

Cytotoxicity of the methanolic extract is appeared to be more active on MDA-MB-231 compare with other cell line. Concentration of $50 \mu \mathrm{g} / \mathrm{mL}$ of methanolic extract decreased the MDA-MB-231 cell viability to $49.7 \%$ while the Chang liver cell viability was $85.8 \%$. Tamoxifen was used as a positive control (Figure 9) in this study. The $\mathrm{IC}_{50}$ concentration of tamoxifen (Table 5) for HT-29, Chang liver cell, MDA-MB-231 and MCF7 were 18.11, 45.07, 17.51 and $17.31 \mu \mathrm{g} / \mathrm{mL}$ respectively. The activity of tamoxifen was found to be higher than that of $C$. aurantium extracts. All the extracts showed cytotoxic effects at various concentrations. Different bioactive compounds and variation of phytochemicals such as phenolics, flavonoids could lead to the cytotoxic activity of this medicinal plant. Mavundza et al. and Oskoueian et al. [19,35] indicated the ability of flavonoids and phenolic compounds to serve as anticancer agents. Zhang et al. [36] showed that kaempferol, quercetin, 
anthocyanins, coumaric acid and ellagic acid isolated from strawberry inhibited the growth of breast (MCF-7), oral (KB, CAL-27), colon (HT-29, HCT-116), and prostate (LNCaP, DU-145) human cancer cell lines. Similar results have also been reported in previous studies stating that polyphenols such as resveratrol, quercetin, catechin, and epicatechin isolated from wine extract [37] and green tea polyphenols like epigallocatechin and epicatechin [38] play important roles as anticancer agents [39-43].

Figure 9. Effect of tamoxifen as a positive control on Chang liver, MCF-7, MDA-MB 231 and HT-29 cells survival. All values represent the mean \pm S.E.M from three independent experiments. $* * * p<0.001, * * p<0.01$ and $* p<0.1$ indicate significant difference compared to the untreated control group.

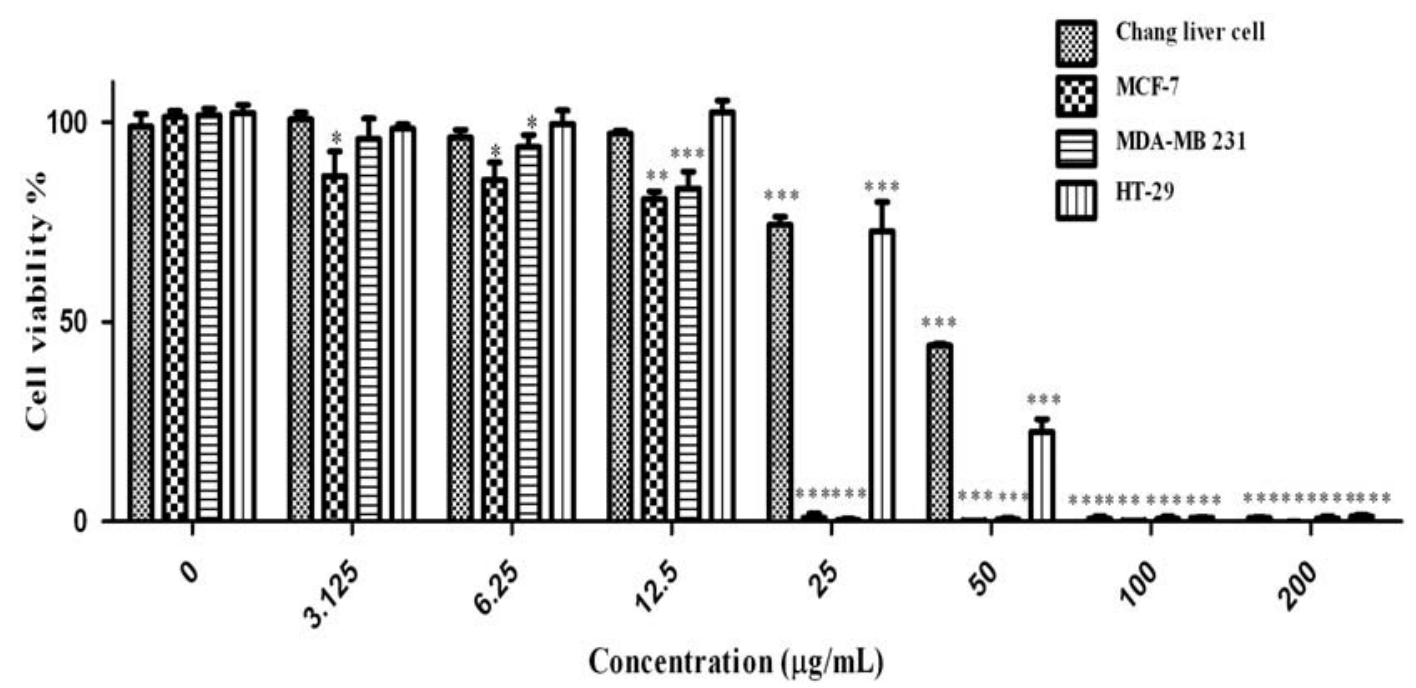

\section{Experimental}

\subsection{Plant Material}

The petals of Citrus aurantium bloom were collected from the fully opened flowers of twenty trees located at three different gardens located in Ramsar, Mazandaran, Iran on April 2007. The samples were freeze-dried, ground to powder using a pestle and mortar. The ground powder was kept in $4{ }^{\circ} \mathrm{C}$ for further experiments.

\subsection{Preparation of Extracts}

The bloom of Citrus aurantium was extracted using three different solvents: ethanol, methanol and hot water. For methanolic and ethanolic extraction method of Crozier et al. [44] was followed with slight modification. Air-dried sample $(0.5 \mathrm{~g})$ weighed and placed into a $100 \mathrm{~mL}$ conical flask, and treated with $80 \%(\mathrm{v} / \mathrm{v})$ ethanol or methanol $(40 \mathrm{~mL})$. It was followed by an addition of $6 \mathrm{M} \mathrm{HCl}(10 \mathrm{~mL})$. The mixture was refluxed for $2 \mathrm{~h}$ at $90{ }^{\circ} \mathrm{C}$ and filtered by using Whatman No. 1 filter paper (Whatman, Welwyn Garden City, UK) continued by evaporation of filtrate using a vacuum rotary evaporator (Buchi, Flawil, Switzerland). The boiling water extraction was carried out according to a method of Gülçin et al. [45]. Five grams of ground citrus blooms were placed in a beaker glass and mixed with boiling water $(100 \mathrm{~mL})$ followed by magnetic stirring for $15 \mathrm{~min}$. The extract was then filtered and 
evaporated as mentioned above. The dried crude extract was weighed and dissolved in methanol and stored at $-20{ }^{\circ} \mathrm{C}$ for further experiments.

\subsection{Total Phenolic Content}

The amount of total phenolic compounds in the citrus extract was determined with the Folin-Ciocalteu's reagent according to Ismail et al. [46] Results of total phenolic contents were expressed as milligrams of gallic acid equivalents (GAE) per gram dry weight (DW).

\subsection{Total Flavonoid Content}

Total flavonoid compound was measured by the aluminum chloride colorimetric assay based on Marinova et al. [3]. Total flavonoid compound of extracts were expressed as mg rutin equivalent/g dry weight (DW).

\subsection{Determination of Phenolic and Flavonoid Compounds by HPLC}

The phenolic and flavonoid compounds of citrus bloom quantitatively measured by reversed-phase high-performance liquid chromatography (HPLC) based on the method described by Crozier et al. [44] with some modifications. Phenolic compounds standards consisted of gallic acid, syringic acid, vanillic acid, salicylic acid, caffeic acid and the flavonoid compounds standards of quercetin, rutin, myricetin, kaempferol, naringin, apigenin, genistein, daidzein, and pyrogallol. An aliquot of sample extract was loaded on an Agilent-1200 series HPLC instrument equipped with a UV-Vis photodiode array (DAD) detector, binary pump, vacuum degasser, auto sampler and analytical column (Intersil ODS-3 5um $4.6 \times 150 \mathrm{~mm}$; Gl Science Inc, Tokyo, Japan). Solvents comprised deionized water and acetonitrile. The $\mathrm{pH}$ of water was adjusted to 2.5 with trifluoroacetic acid. The phenolic and iso-flavonoid compounds were detected at $280 \mathrm{~nm}$ and the flavonoid compounds at $350 \mathrm{~nm}$. The column was equilibrated with $85 \%$ solvent $\mathrm{A}$ (water) and $15 \%$ solvent $\mathrm{B}$ (acetonitrile) then the ratio of solvent $\mathrm{B}$ was increased to $85 \%$ in $50 \mathrm{~min}$ followed by reducing solvent $\mathrm{B}$ to $15 \%$ in $55 \mathrm{~min}$. this ratio was continued to $60 \mathrm{~min}$ for the next analysis with flow rate at $0.6 \mathrm{~mL} / \mathrm{min}$. All the standards were purchased from Sigma Chemical Company.

\subsection{Antioxidant Activity (DPPH Free Radical Scavenging Activity)}

The free radical scavenging activity of the plant extracts was determined using the DPPH assay as described by Gülçin et al. [45]. One $\mathrm{mL}$ of each extract (methanolic, ethanolic and water) of Citrus aurantium petals at different concentration was mixed with $0.1 \mathrm{mM}$ solution of 1,1-diphenyl-2-hydrazyl (DPPH) in methanol (3 mL) and incubated for $30 \mathrm{~min}$ in the dark condition, the absorbance of the mixture was read using a visible spectrophotometer (Novaspec II visblespectro) at $517 \mathrm{~nm}$. BHT and $\alpha$-tocopherol were used as antioxidant standards. Free radical scavenging activity from the sample was calculated according to the formula:

Free radical scavenging activity $=\left[\left(\mathrm{A}_{0}-\mathrm{A}_{1}\right) / \mathrm{A}_{0}\right] \times 100 \%$

where $A_{0}$ was the absorbance of the control reaction and $A_{1}$ was the absorbance in the presence of the sample. 


\subsection{Ferric Reducing Antioxidant Power (FRAP)}

The ferric reducing property of the extracts was determined using an assay described by Yen and Chen [47]. The assay was carried out in triplicate. BHT, $\alpha$-tocoferol and vitamin C were used as standard antioxidants.

\subsection{Anti Inflammatory Assay}

The murine monocytic macrophage cell line RAW 264.7 was cultured in Dulbecco's Modified Eagle Media (DMEM; $2 \mathrm{mM}$ L-glutamine, $45 \mathrm{~g} / \mathrm{L}$ glucose, $1 \mathrm{mM}$ sodium pyruvate, $50 \mathrm{U} / \mathrm{mL}$ penicillin; $50 \mu \mathrm{g} / \mathrm{mL}$ streptomycin) with $10 \%$ foetal bovine serum (FBS). The cells were cultured at $37{ }^{\circ} \mathrm{C}$ with $5 \% \mathrm{CO}_{2}$ and were split twice a week. $1 \times 10^{6}$ cells/mL RAW 264.7 cells were seeded in 96-well tissue culture plate and incubated for $24 \mathrm{~h}$ at $37{ }^{\circ} \mathrm{C}$ with $5 \% \mathrm{CO}_{2}$. The cells were then incubated in prepared DMEM medium containing $100 \mu \mathrm{L}$ of test extract in DMSO and serially diluted to give a final concentration of $100 \mu \mathrm{g} / \mathrm{mL}$ in $0.1 \%$ DMSO. Cells were then stimulated with $200 \mathrm{U} / \mathrm{mL}$ of IFN- $\gamma$ and $10 \mu \mathrm{g} / \mathrm{mL}$ LPS for another $17 \mathrm{~h}$. The presence of nitrite was determined in cell culture media by Griess reagent and absorbance was read at $550 \mathrm{~nm}$ using a microplate reader (Spectra Max Plus 384, Molecular Devices Inc., Sunnyvale, CA, USA). Nitrite concentration in the supernatants was determined by comparison with a sodium nitrite standard curve. The amount of cell viability was detected by MTT cytotoxicity assay. L-NAME was used as iNOS inhibitor (control) at concentration $250 \mu \mathrm{M}[11]$.

\subsection{Anti Cancer Activity Assay}

Human cancer cell lines (MCF-7; MDA-MB-231), human hepatocytes (Chang liver cells) and human colon adenocarcinoma (HT-29) cell lines obtained from the American Type Culture Collection (ATCC) were used in this study. Cells were grown at $37{ }^{\circ} \mathrm{C}$ in humidified $5 \% \mathrm{CO}_{2}$ and $95 \%$ air atmosphere in DMEM. Monolayers of the cells $\left(5 \times 10^{3} / 100 \mu \mathrm{L}\right)$ were grown in 96 -well microtitre plates and exposed to two-fold serial dilution of the extracts from $200 \mu \mathrm{g}$ to $3.1 \mu \mathrm{g} / 100 \mu \mathrm{L}$. After 3 days incubation at $37{ }^{\circ} \mathrm{C}$, the cytotoxicity of extracts was determined by using MTT assay according to Ahmad et al. [48,49]. Tamoxifen, which is a known anticancer drug, was used as a positive control in the present study.

\subsection{Statistical Analysis}

Data were subjected to one-way analysis of variance (ANOVA) using a complete randomized design following the model: $\mathrm{Yi}=\mu+\mathrm{Ti}+$ ei, where $\mu$ is the mean value, Ti is the treatment effect and ei is the experimental error, respectively. Differences in LSD were considered significant at $p<0.05$. GraphPad Prism 5 software (GraphPad Software Inc., San Diego, CA, USA) was used for all the statistical analyses in anti-inflammatory assay [50-53]. 


\section{Conclusions}

Citrus aurantium bloom extracts contained phenolic and flavonoid compounds. The Citrus aurantium bloom extracts showed good antioxidant activity as measured by DPPH radical scavenging activity and ferric reduction power activity. The extracts also actively inhibited the iNOS in macrophages RAW 264.7 cell, induced by LPS and IFN- $\gamma$, indicating their potential as anti-inflammatory agent. The cytotoxicity assay indicated the potential of this medicinal plant as a source of anticancer therapeutic compounds.

\section{Acknowledgments}

The authors would like to thank the Faculty of Agriculture for financial support, and also the Faculty of Biotechnology and Biomolecular Sciences, University of Putra Malaysia (UPM) for the use of laboratory facilities.

\section{Conflict of Interest}

The authors declare no conflict of interest.

\section{References and Notes}

1. Pike, J.; Chandra, R.K. Effect of vitamin and trace element supplementation on immune indices in healthy elderly. Int. J. Vitam. Nutr. Res. 1995, 65, 117-120.

2. Cornwell, D.G.; Jones, K.H.; Jiang, Z.; Lantry, L.E.; Southwell Keely, P.; Kohar, I. Cytotoxicity of tocopherols and their quinones in drug-sensitive and multidrug-resistant leukemia cells. Lipids 1998, 33, 295-301.

3. Marinova, D.; Ribarova, F.; Atanassova, M. Total phenolics and total flavonoids in Bulgarian fruits and vegetables. J. Univ. Chem. Technol. Metall. 2005, 40, 255-260.

4. Ibrahim, M.H.; Jaafar, H.Z.E. Enhancement of leaf gas exchange and primary metabolites, up-regulate the production of secondary metabolites of Labisia Pumila Blume seedlings under carbon dioxide enrichment. Molecules 2011, 16, 3761-3777.

5. Ibrahim, M.H.; Hawa, Z.E.J. Carbon dioxide fertilization enhanced antioxidant compounds in Malaysian Kacip Fatimah (Labisia pumila Blume). Molecules 2011, 16, 6068-6081.

6. Ibrahim, M.H.; Jaafar, H.Z.E. The influence of carbohydrate, protein and phenylanine ammonia lyase on up-regulation of production of secondary metabolites (total phenolics and flavonoid) in Labisia pumila (Blume) Fern-Vill (Kacip Fatimah) under high $\mathrm{CO}_{2}$ and different nitrogen levels. Molecules 2011, 16, 4172-4190.

7. Ibrahim, M.H.; Jaafar, H.Z.E.; Haniff, M.H.; Raffi, M.Y. Changes in growth and photosynthetic patterns of oil palm seedling exposed to short term $\mathrm{CO}_{2}$ enrichment in a closed top chamber. Acta Physiol. Plant. 2010, 32, 305-313.

8. Ibrahim, M.H.; Jaafar, H.Z.E. The relationship of nitrogen and $\mathrm{C} / \mathrm{N}$ on secondary metabolites and antioxidant activities in three varieties of Malaysia Kacip Fatimah (Labisia pumila Blume). Molecules 2011, 16, 5514-5526. 
9. Ibrahim, M.H.; Jaafar, H.Z.E. Photosynthetic capacity, photochemical efficiency and chlorophyll content of three varieties of Labisia pumila Benth. Exposed to open field and greenhouse growing conditions. Acta Physiol. Plant. 2011, 33, 2179-2185.

10. Ibrahim, M.H.; Jaafar, H.Z.E.; Rahmat, A.; Zaharah, A.R. Effects of nitrogen fertilization on synthesis of primary and secondary metabolites in three varieties of Kacip Fatimah (Labisia pumila Blume). Int. J. Mol. Sci. 2011, 12, 5238-5254.

11. Manthey, J.A.; Guthrie, N.; Grohmann, K. Biological properties of citrus flavonoids pertaining to cancer and inflammation. Curr. Med. Chem. 2001, 8, 135-153.

12. Benavente-Garcia, O.; Castillo, J.; Sabater, F.; Del Rio, J.A. Characterisation of S-adenosyl-Lmethionine: Eriodictyol 40-O-methyltransferase from Citrus aurantium. Developmental changes in the levels of 40-O-methoxyflavonoids and S-adenosyl-L-methionine: Eriodictyol 40-Omethyltransferase activity. Plant Physiol. Biochem. 1995, 33, 227-263.

13. Ejaz, S.; Ejaz, A.; Matsuda, K.; Chae, W.L. Limonoids as cancer chemopreventive agents. J. Sci. Food Agric. 2006, 86, 339-345.

14. Ghasemi, K.; Ghasemi, Y.; Ebrahimzadeh, M. Antioxidant activity, phenol and flavonoid contents of 13 Citrus species peels and tissues. Pak. J. Pharm. Sci. 2009, 22, 277-281.

15. Antolovich, M.; Prenzler, P.; Patsalides, E.; McDonald, S.; Robards, K. Methods for testing antioxidant activity. Analyst 2002, 127, 183-198.

16. Naczk, M.; Shahidi, F. Extraction and analysis of phenolics in food. J. Chromatogr. A 2004, 1054, 95-111.

17. Pérez, M.B.; Calderón, N.L.; Croci, C.A. Radiation-induced enhancement of antioxidant activity in extracts of rosemary (Rosmarinus officinalis L.). Food Chem. 2007, 104, 585-592.

18. Karimi, E.; Oskoueian, E.; Hendra, R.; Jaafar, H.Z.E. Evaluation of Crocus sativus L. stigma phenolic and flavonoid compounds and its antioxidant activity. Molecules 2010, 15, 6244-6256.

19. Oskoueian, E.; Abdullah, N.; Zuhainis, S.W.; Omar, A.R.; Ahmad, S.; Kuan, W.B.; Zolkifli, N.A.; Hendra, R.; Ho, Y.W. Antioxidant, anti-inflammatory and anticancer activities of methanolic extracts from Jatropha curcas Linn. J. Med. Plant Res. 2011, 5, 49-57.

20. Peleg, H.; Naim, M.; Rouseff, R.L.; Zehavi, U. Distribution of bound and free 376 phenolic acids in oranges (Citrus sinensis) and grapefruits (Citrus paradisi). J. Sci. Food Agric. 1991, 57, 417-426.

21. Kong, K.W.; Khoo, H.E.; Prasad, K.N.; Ismail, A.; Tan, C.P.; Rajab, N.F. Revealing the power of the natural red pigment lycopene. Molecules 2010, 15, 959-987.

22. Fukumoto, L.; Mazza, G. Assessing antioxidant and prooxidant activities of phenolic compounds. J. Agric. Food Chem. 2000, 48, 3597-3604.

23. Nijveldt, R.; Nood, E.; Hoorn, D.; Boelens, P.; Norren, K.; Leeuwen, P. Flavonoids: A review of probable mechanisms of action and potential applications. Am. J. Clin. Nutr. 2001, 74, 418-425.

24. Wang, Y.C.; Chuang, Y.; Hsu, H. The flavonoid, carotenoid and pectin content in peels of citrus cultivated in Taiwan. Food Chem. 2008, 106, 277-284.

25. Burda, S.; Oleszek, W. Antioxidant and antiradical activities of flavonoids. J. Agric. Food Chem. 2001, 49, 2774-2779.

26. Majo, D.D.; Giammanco, M.; Guardia, L.M.; Tripoli, E.; Giammanco, S.; Finotti, E. Flavanones in Citrus fruit: Structure antioxidant activity relationships. Food Res. Int. 2005, 38, 1161-1166. 
27. Rapisarda, P.; Tomaino, A.; Cascio, L.R.; Bonina, F.; Pasquale, D.A.; Saija, A. Effectiveness as influenced by phenolic content of fresh orange juices. J. Agric. Food Chem. 1999, 47, 4718-4723.

28. Sumanont, Y.; Murakami, Y.; Tohda, M.; Vajragupta, O.; Matsumoto, K.; Watanabe, H. Evaluation of the nitric oxide radical scavenging activity of manganese complexes of curcumin and its derivative. Biol. Pharm. Bull. 2004, 27, 170-173.

29. Kazlowska, K.; Hsu, T.; Hou, C.; Yang, W.; Tsai, G. Anti-inflammatory properties of phenolic compounds and crude extract from Porphyra dentata. J. Ethnopharmacol. 2010, 128,123-130.

30. Vongtau, H.O.; Abbah, J.; Ngazal, I.E.; Kunle, O.F.; Chindo, B.A.; Otsapa, P.B.; Gamaniel, K.S. Anti-nociceptive and anti-inflammatory activities of the methanolic extract of Parinari polyandra stem bark in rats and mice. J. Ethanopharmacol. 2004, 90, 115-121.

31. Osadebe, P.O.; Okoye, F.B.C. Anti-inflammatory effects of crude methanolic extract and fractions of Alchornea cordifolia leaves. J. Ethanopharmacol. 2003, 89, 19-24.

32. Rotelli, A.E.; Guardia, T.; Juárez, A.O.; Rocha, D.N.E.; Pelzer, L.E. Comparative study of flavonoids in experimental models of inflammation. Pharmacol. Res. 2003, 48, 601-606.

33. Fresco, P.; Borges, F.; Diniz, C.; Marques, M.P. New insights on the anticancer properties of dietary polyphenols. Med. Res. Rev. 2006, 26, 747-766.

34. Boik, J. Natural Compounds in Cancer Therapy; Oregon Medical Press: Garden City Park, NY, USA, 2001.

35. Mavundza, E.J.; Tshikalange, T.E.; Lall, N.; Hussein, A.A.; Mudau, F.N.; Meyer, J.J.M. Antioxidant activity and cytotoxicity effect of flavonoids isolated from Athrixia phylicoides. J. Med. Plant Res. 2010, 4, 2584-2587.

36. Zhang, J.; Li, Q.; Di, X.; Liu, Z.H.; Xu, G. Layer-by-layer assembly of multicoloured semiconductor quantum dots towards efficient blue, green, red and full color optical films. Nanotechnology 2008, 19, 5606.

37. Kampa, M.; Hatzoglou, A.; Notas, G.; Damianaki, A.; Bakogeorgou, E.; Gemetzi, C.; Kouroumalis, E.; Martin, P.M.; Castanas, E. Wine antioxidant polyphenols inhibit the proliferation of human prostate cancer cell lines. Nutr. Cancer 2000, 37, 223-233.

38. Weisburg, J.H.; Weissman, D.B.; Sedaghat, T.; Babich, H. In vitro anti-cancer of epigallocatechin gallate and tea extracts to cancerous and normal cells from the human oral cavity. Basic Clin. Pharmacol. Toxicol. 2004, 95, 191-200.

39. Ghasemzadeh, A.; Jaafar, H.Z.E.; Asmah, R. Identification and concentration of some flavonoid components in Malaysian young ginger (Zingiber officinale Roscoe) varieties by a high performance liquid chromatography method. Molecules 2010, 15, 6231-6243.

40. Jaafar, H.Z.E.; Mohamed, H.N.B.; Rahmat, A. Accumulation and partitioning of total phenols in two varieties of Labisia pumila Benth. under manipulation of greenhouse irradiance. ISHS Acta Hortic. 2008, 797, 387-392.

41. Karimi, E.; Jaafar, H.Z.E. Bioactive compounds profiling of three varieties of Labisia pumila Benth using HPLC and GC-MS in microwave obtained extracts. Molecules 2011, 16, 6791-6805.

42. Karimi, E.; Jaafar, H.Z.E.; Ahmad, S. Phytochemical analysis and antimicrobial activities of methanolic extracts of leaf, stem and root from different varieties of Labisa pumila Benth. Molecules 2011, 16, 4438-4450. 
43. Karimi, E.; Jaafar, H.Z.E.; Ahmad, S. Phenolics and flavonoids profiling and antioxidant activity of three varieties of Malaysian indigenous medicinal herb Labisia pumila Benth. J. Med. Plant Res. 2011, 5, 1200-1206.

44. Crozier, A.; Jensen, E.; Lean, M.E.J.; McDonald, M.S. Quantitative analysis of flavonoids by reversed-phase high-performance liquid chromatography. J. Chromatogr. A 1997, 761, 315-321.

45. Gulcin, I.; Gungor Sat, I.; Beydemir, S.; Elmastas, M.; Irfan Kufrevioglu, O. Comparison of antioxidant activity of clove (Eugenia caryophylata Thunb) buds and lavender (Lavandula stoechas L.). Food Chem. 2004, 87, 393-400.

46. Ismail, H.I.; Chan, K.W.; Mariod, A.A.; Ismail, M. Phenolic content and antioxidant activity of cantaloupe (cucumis melo) methanolic extracts. Food Chem. 2010, 119, 643-647.

47. Yen, G.C.; Chen, H.Y. Antioxidant activity of various tea extracts in relation to their antimutagenicity. J. Agric. Food Chem. 1995, 43, 27-32.

48. Ahmad, R.; Ali, A.M.; Israf, D.A.; Ismail, N.H.; Shaari, K.; Lajis, N.H. Antioxidant, radical-scavenging, anti-inflammatory, cytotoxic and antibacterial activities of methanolic extracts of some Hedyotis species. Life Sci. 2005, 76, 1953-1964.

49. Oskoueian, E.; Abdullah, N.; Ahmad, S.; Saad, W.Z.; Omar, A.R.; Ho, Y.W. Bioactive compounds and biological activities of Jatropha curcas L. kernel meal extract. Int. J. Mol. Sci. 2011, 12, 5955-5970.

50. Ibrahim, M.H.; Jaafar, H.Z.E.; Asmah, R.; Zaharah, A.R. Involvement of nitrogen on flavonoids, glutathione, anthocyanin, ascorbic acid and antioxidant activities of Malaysian medicinal plant Labisia pumila Blume (Kacip Fatimah). Int. J. Mol. Sci. 2012, 13, 393-408.

51. Oskoueian, E.; Abdullah, N.; Hendra, R.; Karimi, E. Bioactive compounds, antioxidant, xanthine oxidase inhibitory, tyrosinase inhibitory and anti-inflammatory activities of selected agro-industrial by-products. Int. J. Mol. Sci. 2011, 12, 8610-8625.

52. Ghasemzadeh, A.; Jaafar, H.Z.E.; Asmah, R. Antioxidant activities, total phenolics and flavonoids content in two varieties of Malaysia young ginger (Zingiber officinale Roscoe) Molecules 2010, $15,4324-4333$.

53. Karimi, E.; Oskouean, E.; Hendra, R.; Jaafar, H.Z.E. Evaluation of Crocus sativus L. stigma phenolic and flavonoid compounds and its antioxidant activity. Molecules 2010, 15, 6244-6256.

Sample Availability: Samples of the compounds are available from the authors.

(C) 2012 by the authors; licensee MDPI, Basel, Switzerland. This article is an open access article distributed under the terms and conditions of the Creative Commons Attribution license (http://creativecommons.org/licenses/by/3.0/). 